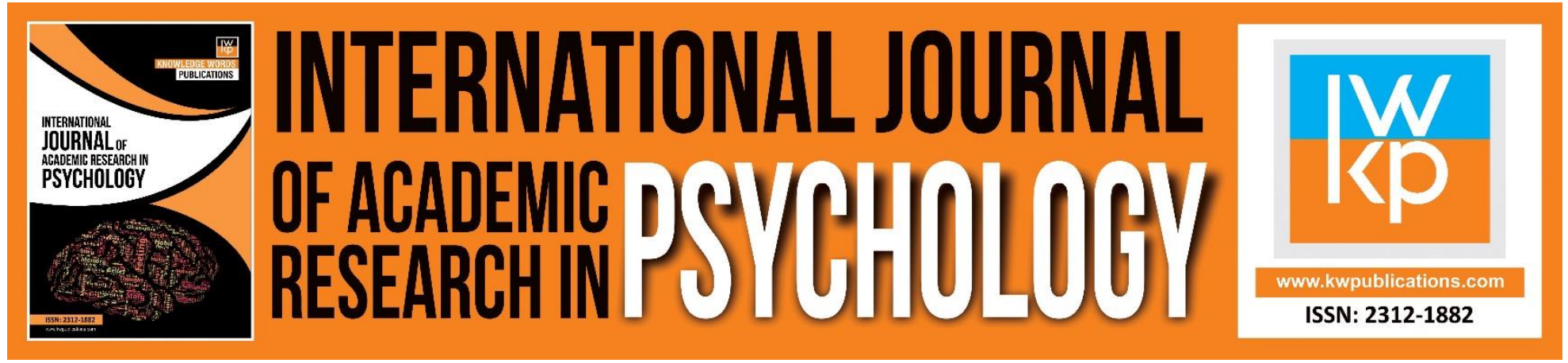

\title{
A Study on Emotional Intelligence among Psychotherapists in Northern Uganda
}

Kabunga Amir, Murithi J. Jesse

To Link this Article: http://dx.doi.org/10.46886/IJARP/v5-i1/2484

DOI:10.46886/IJARP/v5-i1/2484

Received: 18 July 2018, Revised: 20 August 2018, Accepted: 10 September 2018

Published Online: 24 September 2018

In-Text Citation: (Amir, \& Jesse, 2018)

To Cite this Article: Amir, K., Jesse, M. J. (2018). A Study on Emotional Intelligence among Psychotherapists in Northern Uganda. International Journal of Academic Research in Psychology. 5(1), 29-39.

Copyright: (C) 2018 The Author(s)

Published by Knowledge Words Publications (www.kwpublications.com)

This article is published under the Creative Commons Attribution (CC BY 4.0) license. Anyone may reproduce, distribute, translate and create derivative works of this article (for both commercial and non-commercial purposes), subject to full attribution to the original publication and authors. The full terms of this license may be seen

at: http://creativecommons.org/licences/by/4.0/legalcode

Vol. 5, No. 1, 2018, Pg. 29 - 39

https://kwpublications.com/journals/journaldetail/IJARP

JOURNAL HOMEPAGE

Full Terms \& Conditions of access and use can be found at https://kwpublications.com/pages/detail/publication-ethics 


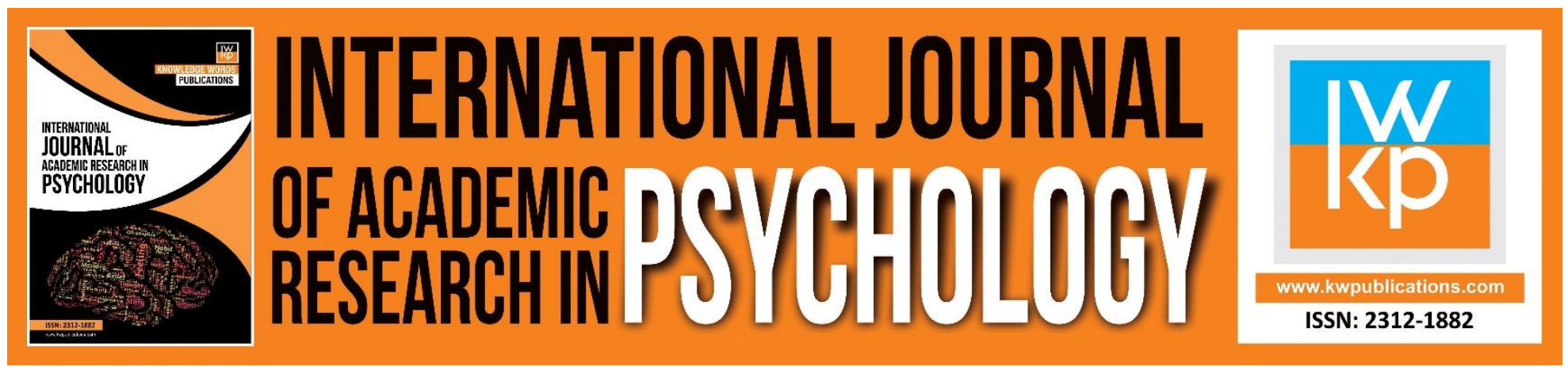

\title{
A Study on Emotional Intelligence among Psychotherapists in Northern Uganda
}

\author{
Kabunga Amir \\ Department of Psychology, Egerton University, Kenya \\ Murithi J. Jesse \\ Department of Education, Presbyterian University of East Africa, Kenya
}

\begin{abstract}
A growing number of studies have suggested that emotional intelligence could have an impact on several individual domains. However, few studies have been done on emotional intelligence among psychotherapists in Africa in general and Uganda in particular. The study was to determine the levels of emotional intelligence among psychotherapists in northern Uganda. Data collection occurred with surveys incorporating the Emotional Competency Inventory 2.0. Psychotherapists from northern Uganda participated with 207 respondents returning completed surveys. Data analysis was done using descriptive statistics including percentages, median, minimum and maximum. Results indicates that $60.0 \%$ possessed high levels of self-awareness, $60.3 \%$ reported high levels of social awareness, $55.6 \%$ scored high in self-management domain and $70.1 \%$ scored highly in social skills. On the basis of these findings, suggestions and recommendations were made to include emotional intelligence as an integral component of training and incorporate emotional intelligence intervention techniques to benefit psychotherapists in managing work related stress.
\end{abstract}

Keywords: Emotional Intelligence, Northern Uganda, Psychotherapists.

\section{Background}

While the roots of emotional intelligence can arguably be traced back to the start of the $20^{\text {th }}$ century, the majority of researches addressing the concept have appeared within the last two decades (Crowne, 2013). The term emotional intelligence was first used in the field of psychology by (Mayer \& Salovey, 1995) in 1990. Emotional intelligence was however, brought to the forefront by Goleman in 1995. Since then the concept has become a major topic of interest in both the public and private practices (Mortana et al., 2014). However, there is lack of precise definition of the concept and consequently, different researchers have defined the notion according to their own perspective. Goleman (1997) defined emotional intelligence as recognising one's feelings and having the ability to manage those feelings to complete tasks and performing at the fullest potential, recognising the feelings of others and having efficient management skills. Mayer, Salovey and Caruso (2000) defined 
emotional intelligence as the ability to perceive, appraise and express emotion accurately and to adapt to different circumstances. Bar-On (2004) referred to emotional intelligence as a set of abilities and non-cognitive skills which aid to cope with environmental stress. According to Gryn (2010) emotional intelligence involves making a distinction between one's own emotions and others and recognising and understanding these emotions. Although, the concept hasn't yet been precisely defined, most definitions demonstrate common themes. They seem to share four aspects; selfawareness, control of emotion, social-awareness and social skills.

The findings of various studies demonstrated that emotional intelligence could have an impact on several individual domains. For instance, emotional intelligence has been found to predict performance (Bar-On, 1997), career success (Ferraro, 2010; Kahn, 2013) and is correlated with better mental and emotional health (Gardner, 2005). Also emotional intelligence is one of the best predictors of adaptive coping strategies to stressful situations (Cabello et al., 2014). Besides, emotional intelligence would facilitate appropriate responses to different events that an individual would have to face daily and would decreases maladaptive emotional reactions by reducing negative moods (MacCann et al., 2011). Conversely, low levels of emotional intelligence are related to selfdestructive acts like drinking and drug abuse (Brown et al., 2012). Therefore emotional intelligence may have influence on the wellbeing of psychotherapists.

Studies show that psychotherapists experience disproportionately high levels of work related stress in comparison with other occupations (Bober \& Regehr, 2006; Pearlman \& Maclan, 1995; Smith et al., 2000). Figley (1995a) has recognized this aspect and described it as a 'cost to caring'. Emotional intelligence in the process of psychotherapy can be regarded as a core built-quality psychotherapy services. Therefore as AbdRahman (2000) suggested psychotherapy services should go through the process of transformation involving the elements of emotional intelligence. An effort should be made to identify the level of emotional intelligence because it provides valuable information for psychotherapists in assessing self-effectiveness to increase the efficiency of psychotherapy skills and personal development. Previous research mostly in western countries has examined emotional intelligence among different professionals including; social workers, physicians, nurses, teachers, relief aid workers, trauma workers to mention a few (Potter et al., 2013; Potter et al., 2010; Klappa et al., 2015). Therefore there is a gap in the literature regarding emotional intelligence among psychotherapists in Uganda. The purpose of this study was to investigate the levels of emotional intelligence among physiotherapists in northern Uganda. The guiding research question in this project is:

What are the levels of emotional intelligence among psychotherapists among in northern Uganda?

\section{Methodology}

This study adopted a quantitative approach using a cross-sectional research design. The respondents in this study were two hundred and seven psychotherapists working in northern Uganda. Emotional Competency Inventory (ECl) 2.0 questionnaires were distributed to respondents using random sampling. $\mathrm{ECl} 2.0$ has 72 items grouped into 18 emotional competencies. These 18 emotional competencies fall into four major dimensions; self-awareness, self-management, social-awareness and social skills. 
INTERNATIONAL JOURNAL OF ACADEMIC RESEARCH IN PSYCHOLOGY

Vol. 5, No. 1, 2018, E-ISSN: 2312-1882 @ 2018 KWP

\section{Demographics of the Respondents}

The gender ratio for the sample group was $56 \%$ male $(n=116)$ and $44 \%$ female $(n=91)$. The age groups in the sample are $41.5 \%$ were between $24-34$ years $(n=86) ; 36.3 \%$ were $35-44$ years $(n=75) ; 19.3 \%$ were $45-54$ years $(n=40)$; and $2.9 \%$ were 55 years and above $(n=6)$. Qualification of the respondents are 3.4\% had masters $(n=7) ; 54.1 \%$ had Bachelors $(n=112) ; 33.3 \%$ had Diploma $(n=69)$ and $9.2 \%$ (19) were Certificate holders. Working experience of the respondents are $20 \%$ had experience of less than 2 years $(n=42) ; 27.5 \%$ were in $2-4$ years $(n=57) ; 40.1 \%$ were in $5-9$ years $(n=583)$; and $12.1 \%$ were in more than 10 years $(n=25)$.

\section{Results and discussion}

The major objective of the study was to determine the levels of emotional intelligence among psychotherapists in northern Uganda. To achieve this objective, the respondents were asked to indicate their competencies on a five point likert scale. Once all the items were scored, emotional intelligence levels of psychotherapists were rated as low, average or high based on the $\mathrm{ECl} 2.0$ technical manual guidelines (Hay Group, 2005). The researchers scored and categorized the levels of emotional intelligence within the four domains.

\section{Self-Awareness Domain}

Self-awareness domain has three competencies namely; emotional awareness, accurate selfassessment and self-confidence. The self-awareness domain had a total of 12 items. The respondents were asked to rate themselves on this domain using the $\mathrm{ECl} 2.0$ questionnaire. Each of the items in this domain had the lowest score of one and highest score of five. Responses to each of three competencies were rated. Data was summarized as median, minimum and maximum. The measures were used to specifically describe the psychotherapists' responses on competencies as indicated in Table 1.

\section{Table 1}

Findings on Psychotherapist Self-Awareness Competencies

\begin{tabular}{llllll}
\hline Domain & Competency & Sample size & Median (IQR) & Min. & Max. \\
\hline Self- & Emotional Awareness & 206 & $16.0(14.0,18.0)$ & 6.0 & 20.0 \\
Awareness & Accurate self-Assessment & 206 & $15.0(13.0,17.0)$ & 8.0 & 19.0 \\
& Self- Confidence & 207 & $16.0(13.0,17.0)$ & 8.0 & 20.0 \\
& Total & 205 & $47.0(39.0,50.0)$ & 30.0 & 58.0 \\
\hline
\end{tabular}

Considering the individual scores of the three competencies, Table 1 indicates that the median score for psychotherapists' self-awareness was 47.0 (IQR: 39.0, 50.0) with a minimum and a maximum of 30.0 and 58.0 respectively. The scores for this domain appear far to the right of the minimum value of 12 that was anticipated in case a respondent scored strongly disagreed with the respective research items. None of the competencies has a minimum score of 4 indicating that no respondent strongly disagreed with the item contributing to the scores for each competency. The high median scores demonstrate better emotional intelligence based on this domain. This was later collapsed into three categories in order to determine the levels of self-awareness among the sampled respondents. The results are illustrated in Table 2. 
INTERNATIONAL JOURNAL OF ACADEMIC RESEARCH IN PSYCHOLOGY

Vol. 5, No. 1, 2018, E-ISSN: 2312-1882 @ 2018 KWP

Table 2

Rating of Psychotherapists' Self-Awareness

\begin{tabular}{llll}
\hline Self-Awareness Scores & Levels & $\mathbf{n}$ & Percentage \\
\hline $0-29$ & Low & 0 & 0.0 \\
$30-45$ & Average & 82 & 40.0 \\
$46-60$ & High & 123 & 60.0 \\
Total & & $\mathbf{2 0 5}$ & $\mathbf{1 0 0}$ \\
\hline
\end{tabular}

The analysis in Table 2 indicates that majority of the respondents (60.0\%) possessed high levels of self-awareness, $40 \%$ of the respondents had average levels of self-awareness and none of the respondents had low levels of self-awareness. The results indicated that the level of self-awareness among psychotherapists was high and significant number had average self-awareness. High scores on self-awareness mean that the majority psychotherapists know their strength and limitations. It can also be deduced from this result that psychotherapists know what environments are optimal for their work style. This concurs with Holahan and Sears (1995) who stated that individuals who are able to recognize their own feelings are more competent in determining their work environment. In addition psychotherapists are able to recognise feelings and put a name on them. This concurs with Goleman's (1995) assertion that one of the basic emotional intelligence skills involves ability to recognise feelings and put a name on them.

This result is consistent with Goleman's (1996) study in which primary school counsellors reported moderate and high levels of self-awareness. Similarly, the result matches the findings of Rorlinda et al.'s (2015) study on emotional intelligence competencies among Malaysian school counsellors. The study showed that schools counsellors had high levels of self-awareness. However, the results contrast a study by Nasir, Mustaffa and Ahmad (2011) which showed that counselling teachers in Kulaijaya, Johor in Malaysia possessed moderate level of self-awareness emotional intelligence. This discrepancy may be attributed to a small sample in the study.

\section{Social Awareness Domain}

Social awareness domain had three competencies namely empathy, organizational awareness and service orientation. Each competency had four items. This domain had a total of 12 items. The psychotherapists were asked to rate themselves on this domain. Each of the items in this domain had the lowest score of one and highest score of five. To determine the psychotherapist responses, measures of central tendency including the median, minimum and maximum were used to specifically describe psychotherapists' social awareness competencies as summarised in Table 3.

Table 2

Findings on Psychotherapist Social Awareness Competencies

\begin{tabular}{llllll}
\hline Domain & Competency & Sample size & Median (IQR) & Min. & Max. \\
\hline Social & Empathy & 207 & $16.0(13.3,18.0)$ & 6.0 & 20.0 \\
Awareness & Organizational Awareness & 206 & $16.0(14.0,17.0)$ & 7.0 & 19.0 \\
& Service orientation & 207 & $16.0(13.0,17.0)$ & 6.0 & 20.0 \\
& Total & 206 & $49.0(41.0,52.0)$ & 25.0 & 58.0 \\
\hline
\end{tabular}

Table 3 indicates that the median score for social awareness was 49.0 (IQR: 41.0, 52.0) with a minimum of 25.0 and a maximum of 58.0. The total for each competency score in this domain appears 
INTERNATIONAL JOURNAL OF ACADEMIC RESEARCH IN PSYCHOLOGY

Vol. 5, No. 1, 2018, E-ISSN: 2312-1882 @ 2018 KWP

far to the right of the minimum value of 12. This was the minimum value of the 5 Likert scale anticipated in case a respondent strongly disagreed with the related research items. Again the high median scores demonstrate better emotional intelligence based on social awareness domain. This was later collapsed into three categories in order to establish the levels of social awareness among psychotherapists in northern Uganda. The results are illustrated in Table 4.

\section{Table 4}

Rating of Psychotherapists' Social Awareness Competencies

\begin{tabular}{llcc}
\hline Social Awareness Scores & Levels & $\mathbf{n}$ & Percentage \\
\hline $0-29$ & Low & 6 & 2.9 \\
$30-45$ & Average & 76 & 36.8 \\
$46-60$ & High & 124 & 60.3 \\
Total & & $\mathbf{2 0 6}$ & $\mathbf{1 0 0}$ \\
\hline
\end{tabular}

The results in Table 4 demonstrated that majority (60.3\%) of the respondents had high levels of social awareness. A significant number (36.8\%) had average social awareness while a small number (2.9\%) of the respondents had low levels of social awareness. The high social awareness suggests that the majority of the psychotherapists in northern Uganda relate well with people of diverse background and consider the opinion of both the clients and colleagues. This concurs with a study by Berr, Church and Wachawski (2000) which found that individuals who consider others' feelings and emotions in the work process are rated by colleagues as being more highly sociable than their counterparts who are not.

The result compares favourably with the reports from previous empirical research (Cook, 2006; Rorlinda et al., 2015). For example in a study on emotional intelligence competencies among Malaysian school counsellors, Rorlinda et al. (2015) report that school counsellors had high scores in the social awareness domain. Cook (2006) reports that principals scored high in social awareness domain. Basing on the sample findings above, less than $2 / 5$ of the psychotherapists in the districts have average competencies in social awareness domain while less than $1 / 10$ are poor in similar competencies. This corresponds to a study by Goleman's (1996), which shows that primary school counsellors of research scored moderately and high in this same domain of emotional intelligence. However results of the present study contradict the findings of a study by Nasir, Mustaffa and Ahmad (2011) which revealed that counselling teachers in Kulaijaya, Johor in Malaysia possessed modest level of social awareness. This inconsistence in results may be attributed a small sample used in Nasir, Mustaffa and Ahmad's (2011) study. In addition, the level of experience for the respondents may also account for this discrepancy.

\section{Self-Management Domain}

Self-management domain comprised of six competencies namely; emotional self-control, transparency, adaptability, achievement orientation, initiative and optimism. Each of the competencies had four items and therefore there were 24 items in total in this domain. The lowest score was 24 and the highest score in this domain was 120. The psychotherapists were asked to indicate their self-evaluation in this domain. To investigate the psychotherapist responses to the research variable, descriptive statistics (median, minimum and maximum) were used. The results are reported in Table 5 . 
INTERNATIONAL JOURNAL OF ACADEMIC RESEARCH IN PSYCHOLOGY

Vol. 5, No. 1, 2018, E-ISSN: 2312-1882 @ 2018 KWP

\section{Table 5}

Summary of Findings on Psychotherapists' Self-Management Competencies

\begin{tabular}{llcccc}
\hline Domain & Competency & Sample size & Median (IQR) & Min. & Max. \\
\hline Self- & Emotional Self- Control & 207 & $14.0(11.0,16.0)$ & 7.0 & 20.0 \\
Management & 207 & $14.0(11.0,17.0)$ & 6.0 & 20.0 \\
& Transparency & 207 & $14.0(11.0,17.0)$ & 6.0 & 20.0 \\
& Adaptability & 207 & $13.0(11.0,17.0)$ & 5.0 & 20.0 \\
& Achievement Orientation & 207 & $12.0(11.0,14.0)$ & 6.0 & 19.0 \\
& Initiative & 207 & $13.0(11.0,16.0)$ & 6.0 & 20.0 \\
& Optimism & 207 & $83.0(67.0,95.0)$ & 52.0 & 112.0 \\
\hline
\end{tabular}

Results in Table 5 show that the median score of self-management of psychotherapists was 83.0 (IQR: 67.0, 95.0) with a minimum of 52.0 and a maximum of 112.0. Apparently, the minimum scores for self-management competencies altogether are twice higher than the expected score of 24 had the respondents strongly disagreed with items assessing each competency. This means that psychotherapists in northern Uganda have high emotional intelligence based on this element. This was later collapsed into three categories in order to make a distinction between the levels of selfmanagement among the sampled respondents. The results are illustrated in Table 6.

Table 3

Rating of Psychotherapists' Self-Management Competencies

\begin{tabular}{llcc}
\hline Self- Management Scores & Levels & Frequency $(\mathbf{n})$ & Percentage \\
\hline $0-53$ & Low & 12 & 5.7 \\
$54-71$ & Average & 80 & 38.7 \\
$72-120$ & High & 115 & 55.6 \\
Total & & $\mathbf{2 0 7}$ & $\mathbf{1 0 0}$ \\
\hline
\end{tabular}

Majority respondents (55.6\%) scored high in self-management domain as shown in Table 6 . A significant proportion (38.7\%) of respondents demonstrated average levels of self-management. An insignificant number $(5.7 \%$, ) had low levels self-management. In view of the current study results, it means that the psychotherapists tend to control and regulate to their emotions. This view is supported by Miyagamwala (2015) who asserts that if individuals are competent in self-management, they can ably regulate their own emotional state. In affirmation, Goleman (1998) adds that high selfmanagement is necessary for a psychotherapist to control self in the event of scary client experience. The results above imply that more than $1 / 2$ of the psychotherapists are highly competent in selfmanagement and less than $2 / 5$ others are averagely competent. Despite the contextual differences, this result corresponds with the Rorlinda et al.'s (2015) study in which it was reported that school counsellors among Malaysian schools have both average and high scores on the self-management domain. Similarly, the current study is consistent with Goleman (1996) findings, in which primary school counsellors scored moderately and high in self-regulation domain. Similar to the findings of the study, Baird and Kracen (2006) found that social workers at a non-governmental organisation had an above average ability to manage their own emotions. The study however contrasts Marshall's (2010) study which found out that principals scored low on self-management. Also the current study contradicts Goleman's (1996) study which showed secondary school counsellor obtained average 
INTERNATIONAL JOURNAL OF ACADEMIC RESEARCH IN PSYCHOLOGY

Vol. 5, No. 1, 2018, E-ISSN: 2312-1882 @ 2018 KWP

scores in self-regulation domain. The findings also contradict a study by Nasir, Mustaffa and Ahmad (2011) which showed that counselling teachers in Kulaijaya, Johor had average level of selfmanagement. The inconsistence in results may be attributed to the difference in tools used to collect data and sample size. In addition, the current study findings contradict previous research partly because of location, contextual, and institutional differences. The study was carried out in northern Uganda, which presents different contexts different from areas of the related research above.

\section{Social Skills Scores}

Social skills domain had six competencies namely; developing others, inspirational leadership, change catalyst, influence, conflict management and teamwork and collaboration. Each of the competencies had four items and therefore there are 24 items in this domain. The lowest score was 24 and the highest score was 120 in this domain. The psychotherapists were asked to rate themselves on this domain. Each of the items in the domain had the lowest score of one and highest score of five. Measures of central tendency were used as part of the descriptive statistics for analysis of ECI 2.0 responses. The median, minimum, and maximum were used to specifically describe psychotherapists' competencies in social skills as shown in Table 7.

\section{Table 7}

Summary of Findings on Psychotherapists' Social Skills

\begin{tabular}{lllllc}
\hline Domain & Competency & Sample size & Median (IQR) & Min. & Max. \\
\hline Social & Developing others & 207 & $15.0(12.0,17.0)$ & 6.0 & 20.0 \\
skills & Inspirational Leadership & 207 & $14.0(11.0,16.5)$ & 6.0 & 20.0 \\
& Change catalyst & 207 & $15.0(12.0,16.0)$ & 7.0 & 20.0 \\
& Influence & 207 & $15.0(12.0,16.0)$ & 7.0 & 20.0 \\
& Conflict management & 207 & $15.0(11.0,17.0)$ & 6.0 & 20.0 \\
& Teamwork & 207 & $15.0(11.0,17.0)$ & 6.0 & 20.0 \\
& Total & 207 & $92.0(68.0,98.0)$ & 48.0 & 112.0 \\
\hline
\end{tabular}

The results in Table 7, show that median score was 92.0 (IQR: 68.0, 98.0) with a minimum of 48.0 and a maximum of 112.0. The minimum score for this social skills domain appears far to the right of the minimum value of 24 that was anticipated in case a respondent scored strongly disagreed. Specifically, the median scores are high as regards psychotherapists' social skills in developing others, inspirational leadership, change catalyst, influence, conflict management and teamwork. The high scores for the social skills domain also demonstrate higher emotional intelligence among the respondents. This was later categorised into three in order to separate between the levels of social skills among the sampled respondents. The results were as shown in Table 8. 
INTERNATIONAL JOURNAL OF ACADEMIC RESEARCH IN PSYCHOLOGY

Vol. 5, No. 1, 2018, E-ISSN: 2312-1882 @ 2018 KWP

\section{Table 4}

Rating of Psychotherapists' Social Skills

\begin{tabular}{llcc}
\hline Social- Skills Scores & Levels & Frequency $(\mathbf{n})$ & Percentage \\
\hline $0-53$ & Low & 14 & 6.7 \\
$54-71$ & Average & 48 & 23.2 \\
$72-120$ & High & 145 & 70.1 \\
Total & & $\mathbf{2 0 7}$ & $\mathbf{1 0 0}$ \\
\hline
\end{tabular}

Table 8 indicates that $70.1 \%$ of respondents scored high on social skills domain and $23.2 \%$, had average levels of social skills domains and $6.7 \%$ had low levels of social skills. The high scores in social skills domain imply that psychotherapists can collaborate with colleagues, have inspirational leadership skills, are open to change and are visionary. Application of the competencies of social skills domain by psychotherapists was evident from their rating. This implies that psychotherapists in the region are able to interact comfortably with others, persuade, negotiate and settle disputes amicably. This observation matches a view by Salovey and Mayer (1993) who argue that an individual with good social skills will be able to interact comfortably with co-workers, negotiate and settle disputes peacefully.

The findings of this study are consistent with Goleman's (1996) study in which primary school psychotherapists scored moderately and high in social skills domain. The findings also concur with the Rorlinda et al.'s (2015) study on emotional intelligence competencies among Malaysian school counsellors. The overall findings show that school counsellors had high scores on the social skills domain. This result also corroborates the Michele's (2011) report which indicated that principals of high achieving middle schools exhibited high levels of emotional intelligence. The finding on psychotherapists' self-rating in this domain support the ones by Cook (2006) who reported that principals studied had high levels of social skills domain. In addition, a study by Nasir, Mustaffa and Ahmad (2011) showed that counselling teachers in Kulaijaya, Johor had high level of social skills as a domain of emotional intelligence.

The result of the current study however contrasts with several previous studies (Goleman, 1996; Marshall, 2010; Sharif, Zaidatul \& Rashid, 2012). Sharif, Zaidatul and Rashid (2012) in their study on the relationship between the levels of emotional intelligence and personal development of secondary school counsellors in Johor, discovered that majority of the respondents had moderate level of social skills. Marshall (2010) found out in his study that social skills scores of the school principals were low, while Goleman (1996) also found out secondary school counsellor obtained average scores in social skills domain. The current study findings vary from such previous research partly because of location, contextual, and institutional differences.

\section{Conclusion and Recommendation}

The study showed that psychotherapists in northern Uganda have high emotional intelligence and a reasonable number had low levels of emotional intelligence. Therefore the study concluded that psychotherapists performed better in various aspects of life. They responded appropriately to different events that they would have to face on a daily basis. However, the rating of psychotherapists as average in emotional intelligence may be attributed to the training of psychotherapists which does not include such competencies. The study therefore recommends that there is need to promote emotional intelligence because it comprises of pathways that may help a psychotherapists to adapt 
INTERNATIONAL JOURNAL OF ACADEMIC RESEARCH IN PSYCHOLOGY

Vol. 5, No. 1, 2018, E-ISSN: 2312-1882 @ 2018 KWP

to change and manage adverse life experiences. In addition, on the basis of these findings, suggestions and recommendations were made to include emotional intelligence as an integral component of training and incorporate emotional intelligence intervention techniques to benefit psychotherapists in managing work related stress. There is need for a study to determine the relationship between levels of emotional intelligence and work related strains including compassion fatigue among psychotherapists.

\section{Acknowledgement}

We want to say a big thank you to all my respondents in northern Uganda. You have been very supportive and cooperative. We would like to thank you for your valuable time spent on completing the survey.

\section{Corresponding Author}

Murithi J. Jesse

Department of Education, Presbyterian University of East Africa, Kenya

\section{References}

Abdul Aziz, A. R. (2000). Kemahiran Sosial Asas. Kuala Lumpur: Utusan \& Publication Distributors Sdn. Bhd.

Baird, K., \& Kracen, A. C. (2006). Vicarious traumatization and secondary traumatic stress: A research synthesis. Counselling Psychology Quarterly, 19(2), 181-188.

Bar-On, R. (1997). In Bar-On emotional quotient inventory: Technical Manual. Toronto, ON: MultiHealth Systems.

Bar-On, R. (2004). The Bar-On Emotional Quotient Inventory (EQ-i): Rationale, description and psychometric properties. In G. Geher (Ed.), Measuring emotional intelligence: Common ground and controversy. Hauppauge, NY: Nova Science.

Berr, S., Church, A., \& Waclawski, J. (2000). The right relationship is everything linking personality preference to managerial behaviours. Journal of Human resource development quarterly, Vol. III.

Bober, T., \& Regehr, C. (2006) Strategies for reducing secondary or vicarious trauma: Do they work? Brief Treatment and Crisis Intervention, 6, 1-9.

Brown, C., Chiu, Edmond, N. L., Tobin, J., Reid, J. (2012). Is low emotional intelligence a primary causal factor in drug and alcohol addiction? Australian Academic Press, 91-101.

Cabello, R., Bravo, N. B., Latorre, J. M., and Fernández-Berrocal, P. (2014). Ability of university level education to prevent age-related decline in emotional intelligence. Front. Aging Neurosci. 6:37. doi: 10.3389/fnagi.2014.00037.

Crowne, K. A. (2013). Cultural Exposure, Emotional Intelligence and Cultural Intelligence: An Exploratory Study. International Journal of Cross Cultural Management, 13 (1): 5-22.

Ferraro, J. (2010). Developing emotional intelligence. Psychotherapist NYC. Retrieved from http://psychotherapist-nyc.blogspot.com/2010/09/developing-emotional-intelligence.html.

Figley, C. R. (1995a). Compassion fatigue as secondary traumatic stress disorder: an overview. In C. R. Figley (Ed.), Compassion fatigue: coping with secondary traumatic stress disorder in those who treat the traumatized (pp. 1-20). New York: Brunner/Mazel. 
INTERNATIONAL JOURNAL OF ACADEMIC RESEARCH IN PSYCHOLOGY

Vol. 5, No. 1, 2018, E-ISSN: 2312-1882 @ 2018 KWP

Gryn, M. (2010). The relationship between emotional intelligence and job performance of call centre leaders. (Unpublished masters' thesis). University of South Africa, South Africa.

Kahn, J. (2013). Can emotional intelligence be taught? Retrieved May 28, 2015, fromhttp://www.nytimes.com/2013/09/15/magazine/can-emotional-intelligence-betaught.html?pagewanted=all\&_r=0.

Klappa, S. G., Howayek, R., Reed, K., Scherbarth, B., Klappa, S. P. (2015). Compassion fatigue among new graduate physical therapists. Global Journal of Medicine, Physical and Health Education 3(4), 100-111.

MacCann, C., Fogarty, G. J., Zeidner, M., and Roberts, R. D. (2011). Coping mediates the relationship between emotional intelligence (EI) and academic achievement. Contemp. Educ. Psychol. 36, 60-70. doi:10.1016/j.cedpsych.2010.11.002.

Marshall, I. A. (2010). Emotional Intelligence and Principal Leadership: An Evaluation of Relevance. Pine Hill St. Michael: Erdiston Teachers' Training College.

Mayer, J. D., \& Salovey, P. (1995). Emotional intelligence and the construction and regulation of feelings. Applied and Preventive Psychology, 4.197-208.

Mayer, J. D., Salovey, P., \& Caruso, D. R. (2000). Models of emotional intelligence. In R. J. Sternberg (Ed.). New York: Cambridge. Handbook of Human Intelligence (2nd ed), pp 396-420.

Michele, R. (2011). An Investigation of the Emotional Intelligence Competencies of National Middle Schools to Watch Principals. Retrieved February 2014, from Online Theses and Dissertations: http://encompass.eku.edu/etd/42.

Miyagamwala, G. (2015). Emotional intelligence and teacher effectiveness- an analysis. The Business \& Management Review, Volume 5 Number 4, pp 233-238.

Mortana, R. A., Ripolla, P., Carvalhob, C., Bernala, M. C. (2014). Effects of emotional intelligence on entrepreneurial intention and self-efficacy. Journal of Work and Organizational Psychology, 30, 97-104.

Nasir, M., Mustaffa, Z. A., Ahmad, R. (2011). The relationship between emotional intelligence with skills competency and personal development among counselling teachers in Kulaijaya District, Johor, IJFPSS, Vol.1, No.1, pp. 17-20.

Pearlman, L. A., \& Maclan, P. S. (1995). Vicarious traumatization: An empirical study of the effects of trauma work on trauma therapists. Professional Psychology: Research and Practice, 26, 558565.

Potter, P., Deshields, T., Berger, J., Clarke, M., Olsen, S., Chen, L. (2013). Evaluation of a compassion fatigue resiliency program for oncology nurses. Oncology Nursing Forum. 40(2): 180-187.

Rorlinda, Y., Noriah, M. I., Jamaliah, H., Mohd, H. Z., \& Abu Yazid, A. (2015). Emotional intelligence competencies among Malaysian school's counsellor. International Journal for Research in Emerging Science and Technology, -2, (3), 32-41.

Schunk, D. H., \& Meece, J. L. (2005). Self-efficacy development in adolescence, in F, Pajares \& T. Urdan (eds.), Smith, A., Brice, C., Collins, A., Matthews, V., \& McNamara, R. (2000). The scale of occupational stress: a further analysis of the impact of demographic factors and type of job (Health and Safety Executive Contract Research Report 311/2000). UK: Cardiff University.

Sharif, M., Zaidatul, N., Rashid, A., \& Mohd, N. (2013). Emotional intelligence, skills competency and personal development among counseling teachers. Procedia - Social and Behavioural Sciences (93) $2219-2223$. 